\title{
Review Update
}

\section{Strengthening the reporting of observational studies in epidemiology (STROBE) statement: New guidelines for reporting observational studies \\ C Abeysena}

A vast majority of observational studies have been reported in journals compared to the experimental studies. ${ }^{1}$ Many of those are cross sectional, casecontrol and cohort studies. These study designs are used not only to determine the risk factors for diseases but also to determine the prognostic factors as well. Observational studies also have a role in describing and determining harms of medical interventions. In some situations where the randomized trials are not appropriate or feasible for assessing interventions, observational studies are the alternatives. Therefore observational studies are useful not only for improving public health by changing policies but also for clinical practice.

However, the information provided in published observational studies have many deficiencies. The essential information is not reported at all or, though reported, sometimes appear to be unclear. For example, a review of longitudinal studies on stroke found that 17 out of 49 articles did not report eligibility criteria for recruiting participants. ${ }^{2}$ Readers need to know what was planned (and what was not), what was done, what was found, and what the results mean. The assessment of the strengths and weaknesses of the studies reported in the medical literature is hampered by incomplete, inadequate and inaccurate reporting of research. Transparent reporting of research has many advantages. It allows the critical appraisement of the research articles and it will ultimately facilitate to assess the quality of the studies. It also facilitates adequate inclusion of data which are essential to be extracted for conducting systematic reviews.

The STROBE statement is a checklist of items that should be addressed in articles reporting the three main study designs of analytical epidemiology: cohort, case-control, and cross sectional studies. ${ }^{3}$ The authors of the STROBE claim that the intention is solely to provide guidance on how to report observational research well. ${ }^{3}$ These recommendations are used for neither prescriptions for designing/ conducting studies nor an instrument to evaluate the quality of observational research. The STROBE statement is being endorsed by a growing number of biomedical journals to improve the quality of reporting (www.strobe-statement.org). The authors strongly recommend using the STROBE checklist in conjunction with the explanatory article, which is available freely on the websites of the publishing journals. $^{4}$

The STROBE initiative was established in 2004 including editorial staff from several international journals as well as epidemiologists, methodologists, statisticians, and practitioners. The STROBE statement is a checklist of 22 items that is considered essential for good reporting of observational studies (table). These items are related to the article's title and abstract (item 1), the introduction (items 2 and 3 ), methods (items 4-12), results (items 13-17), discussion sections (items 18-21), and other information (item 22 on funding). Eighteen items are common to all three designs, while four (items $6,12,14$, and 15) are design specific, with different versions for all or part of the item. For some items (indicated by asterisks), information should be given separately for cases and controls in case-control studies, or exposed and unexposed groups in cohort and cross sectional studies. Although the table is a single checklist, the STROBE website provides separate checklists for each of the three study designs.

The STROBE statement should not be interpreted as an attempt to prescribe the reporting of observational research in a rigid format. The checklist items should be addressed in sufficient detail and with clarity somewhere in an article, but the order and format for presenting information depends on author preferences, journal style, and the traditions of the research field. The authors do not aim at standardising reporting. ${ }^{3}$

The authors stress the fact that STROBE and other recommendations on the reporting of research should be seen as evolving documents that require continual assessment, refinement, and, if necessary, change. They invite readers to submit their comments through the STROBE website.

1. Consultant Community Physician and Senior Lecturer, Faculty of Medicine, University of Kelaniya.

Correspondence: 


\begin{tabular}{|c|c|c|}
\hline \multirow[t]{2}{*}{ Title and abstract } & \multirow[t]{2}{*}{1} & $\begin{array}{l}\text { (a) Indicate the study's design with a commonly used term in the title or } \\
\text { the abstract }\end{array}$ \\
\hline & & $\begin{array}{l}\text { (b) Provide in the abstract an informative and balanced summary of what } \\
\text { was done and what was found }\end{array}$ \\
\hline \multicolumn{3}{|l|}{ Introduction } \\
\hline Background/rationale & 2 & $\begin{array}{l}\text { Explain the scientific background and rationale for the investigation be- } \\
\text { ing reported }\end{array}$ \\
\hline Objectives & 3 & State specific objectives, including any prespecified hypotheses \\
\hline \multicolumn{3}{|l|}{ Methods } \\
\hline Study design & 4 & Present key elements of study design early in the paper \\
\hline Setting & 5 & $\begin{array}{l}\text { Describe the setting, locations, and relevant dates, including periods of } \\
\text { recruitment, exposure, follow-up, and data collection }\end{array}$ \\
\hline Participants & 6 & $\begin{array}{l}\text { (a) Cohort study - Give the eligibility criteria, and the sources and meth- } \\
\text { ods of selection of participants. Describe methods of follow-up } \\
\text { Case-control study-Give the eligibility criteria, and the sources and } \\
\text { methods of case ascertainment and control selection. Give the rationale } \\
\text { for the choice of cases and controls } \\
\text { Cross-sectional study-Give the eligibility criteria, and the sources and } \\
\text { methods of selection of participants }\end{array}$ \\
\hline
\end{tabular}

(b) Cohort study-For matched studies, give matching criteria and number of exposed and unexposed

Case-control study-For matched studies, give matching criteria and the number of controls per case

\begin{tabular}{|c|c|c|}
\hline Variables & 7 & $\begin{array}{l}\text { Clearly define all outcomes, exposures, predictors, potential confound- } \\
\text { ers, and effect modifiers. Give diagnostic criteria, if applicable }\end{array}$ \\
\hline Data sources/ measurement & $8^{*}$ & $\begin{array}{l}\text { For each variable of interest, give sources of data and details of methods } \\
\text { of assessment (measurement). Describe comparability of assessment } \\
\text { methods if there is more than one group }\end{array}$ \\
\hline Bias & 9 & Describe any efforts to address potential sources of bias \\
\hline Study size & 10 & Explain how the study size was arrived at \\
\hline Quantitative variables & 11 & $\begin{array}{l}\text { Explain how quantitative variables were handled in the analyses. If ap- } \\
\text { plicable, describe which groupings were chosen and why }\end{array}$ \\
\hline Statistical methods & 12 & $\begin{array}{l}\text { (a) Describe all statistical methods, including those used to control for } \\
\text { confounding }\end{array}$ \\
\hline
\end{tabular}

(b) Describe any methods used to examine subgroups and interactions

(c) Explain how missing data were addressed

(d) Cohort study - If applicable, explain how loss to follow-up was addressed

Case-control study - If applicable, explain how matching of cases and controls was addressed

Cross-sectional study - If applicable, describe analytical methods taking account of sampling strategy

(e) Describe any sensitivity analyses 


\begin{tabular}{|c|c|c|}
\hline \multicolumn{3}{|l|}{ Results } \\
\hline \multirow[t]{3}{*}{ Participants } & $\begin{array}{c}13 \\
*\end{array}$ & $\begin{array}{l}\text { (a) Report numbers of individuals at each stage of study-eg numbers potentially } \\
\text { eligible, examined for eligibility, confirmed eligible, included in the study, complet- } \\
\text { ing follow-up, and analysed }\end{array}$ \\
\hline & & (b) Give reasons for non-participation at each stage \\
\hline & & (c) Consider use of a flow diagram \\
\hline \multirow[t]{3}{*}{$\begin{array}{l}\text { Descriptive } \\
\text { data }\end{array}$} & $\begin{array}{c}14 \\
*\end{array}$ & $\begin{array}{l}\text { (a) Give characteristics of study participants (eg demographic, clinical, social) and } \\
\text { information on exposures and potential confounders }\end{array}$ \\
\hline & & (b) Indicate number of participants with missing data for each variable of interest \\
\hline & & (c) Cohort study-Summarise follow-up time (eg, average and total amount) \\
\hline \multirow[t]{3}{*}{ Outcome data } & 15 & Cohort study - Report numbers of outcome events or summary measures over time \\
\hline & & $\begin{array}{l}\text { Case-control study-Report numbers in each exposure category, or summary meas- } \\
\text { ures of exposure }\end{array}$ \\
\hline & & Cross-sectional study-Report numbers of outcome events or summary measures \\
\hline \multirow[t]{3}{*}{ Main results } & 16 & $\begin{array}{l}\text { (a) Give unadjusted estimates and, if applicable, confounder-adjusted estimates and } \\
\text { their precision (eg, } 95 \% \text { confidence interval). Make clear which confounders were } \\
\text { adjusted for and why they were included }\end{array}$ \\
\hline & & (b) Report category boundaries when continuous variables were categorized \\
\hline & & $\begin{array}{l}\text { (c) If relevant, consider translating estimates of relative risk into absolute risk for a } \\
\text { meaningful time period }\end{array}$ \\
\hline Other analyses & 17 & $\begin{array}{l}\text { Report other analyses done-eg analyses of subgroups and interactions, and sensitiv- } \\
\text { ity analyses }\end{array}$ \\
\hline \multicolumn{3}{|l|}{ Discussion } \\
\hline Key results & 18 & Summarise key results with reference to study objectives \\
\hline Limitations & 19 & $\begin{array}{l}\text { Discuss limitations of the study, taking into account sources of potential bias or im- } \\
\text { precision. Discuss both direction and magnitude of any potential bias }\end{array}$ \\
\hline Interpretation & 20 & $\begin{array}{l}\text { Give a cautious overall interpretation of results considering objectives, limitations, } \\
\text { multiplicity of analyses, results from similar studies, and other relevant evidence }\end{array}$ \\
\hline Generalisability & 21 & Discuss the generalisability (external validity) of the study results \\
\hline \multicolumn{3}{|c|}{ Other information } \\
\hline Funding & 22 & $\begin{array}{l}\text { ve the source of funding and the role of the funders for the present study and, if } \\
\text { plicable, for the original study on which the present article is based }\end{array}$ \\
\hline
\end{tabular}

*Give information separately for cases and controls in case-control studies and, if applicable, for exposed and unexposed groups in cohort and cross-sectional studies.

\section{References}

1. Glasziou P, Vandenbroucke JP, Chalmers I. Assessing the quality of research. BMJ 2004;328:39-41.

2. Tooth L, Ware R, Bain C, Purdie DM, Dobson A. Quality of reporting of observational longitudinal research. Am J Epidemiol 2005;161:280-8.

3. Erik von Elm, Douglas G Altman, Matthias Egger, Stuart J Pocock, Peter C Gøtzsche, Jan P Vandenbroucke. Strengthening the reporting of observational studies in epidemiology (STROBE) statement: guidelines for reporting observational studies BMJ 2007;335:806-808

4. Vandenbroucke JP, von Elm E, Altman DG, Gøtzsche PC, Mulrow CD, Pocock SJ, et al. Strengthening the reporting of observational studies in epidemiology (STROBE): explanation and elaboration. Epidemiology 2007; 18:805-35. 